\title{
Inter-University Networking in Mathematical Digital Blended Learning
}

\author{
Yury I. Dimitrienko ${ }^{1}$, Anastasia V. Chibisova ${ }^{1 *}$, and Victor $Y u$.Chibisov ${ }^{1}$ \\ ${ }^{1}$ Bauman Moscow State Technical University, 2nd Baumanskaya str., 5/1, 105005, Moscow, Russia
}

\begin{abstract}
The concept of blended learning assumes that the student should optimally and in the aggregate use all the opportunities provided by both traditional learning and new digital educational technologies. Blended learning combines the benefits of traditional and e-learning. The use of various models of blended learning allows you to introduce innovative educational technologies into the educational process and build individual educational trajectories for students. Networking contracts are used to effectively implement blended learning at universities. This increases the availability and quality of education, forms unique competencies for training specialists at the intersection of various areas of science and technology, makes it possible to use the material and human resources of other organizations in educational activities, reduces the costs of an educational organization and expands access to modern educational technologies. The article discusses network engineering partnership on the example of BMSTU.
\end{abstract}

\section{Introduction}

Technological advances and digital innovation are increasingly affecting all aspects of education. Blended and online learning is actively developing, which contributes to the modernization and optimization of traditional education. The organization of the educational process using distance learning technologies significantly expands the capabilities of the educational system.

Universities are actively introducing online learning into their educational programs, offering opportunities for those students who cannot attend classes in person. This type of training helps students reduce costs, save time, and develop digital skills and lifelong learning [1].

Online learning also offers the following range of benefits, for example:

- $\quad$ access to materials and content anytime and anywhere;

- $\quad$ students play an active role in the learning process;

- knowledge management among students (exchange of ideas, opinions, practice, experience);

- $\quad$ feedback from the teacher.

* Corresponding author: anachibisova@bmstu.ru 
The number of students who are trained using online technologies is significantly increasing, which leads to the fact that in higher educational institutions there is a need to acquire the appropriate technological infrastructure, introduce the most appropriate management systems and adapt the educational process in accordance with modern trends [2].

Students can study some courses on their own, but many disciplines must be accompanied by classes in classrooms and contact with the teacher.

In search of an optimal balance between full-time and online education, educational organizations are introducing blended learning into the educational process. The concept of blended learning assumes that the student should optimally and in the aggregate use all the opportunities provided by both traditional learning and new educational technologies [3].

Many authors research the effectiveness and efficiency of blended learning, as it combines modern educational technologies and classical teaching methods [4].

Learning technologies used in the blended learning model can help achieve goals not only at the course and program level, but also at the institutional level $[5,6]$.

For the successful implementation of blended learning, the training of highly qualified specialists and the innovative development of education, a promising area is cooperation with other universities - the creation of network partnerships.

\section{Blended learning models}

Blended learning is an educational program that combines online learning with traditional teaching methods and allows students to learn anytime, anywhere [7].

The learning process in blended learning is a sequence of learning phases that alternate in time. It represents a non-classical form of education and attracts students and teachers with its flexibility and modern ways of providing information [8].

The combination of online and offline elements makes learning effective, cost-effective and convenient, and the learning process is interactive, person-centered and adaptive for all interested parties in learning.

Various models of blended education are used in the educational process. The most popular ones are Rotation, Flex, A La Carte and Enriched Virtual.

1. Rotation model - differentiation of forms of education. When mastering an educational program, study time is distributed between classroom training and online training. Training can take place in small groups, include joint projects and individual assignments.

a. Station Rotation - studying a course or subject according to a set schedule and alternating ways of studying the material. Classes are usually held inside the educational institution.

b. Lab Rotation - online training takes place in a special computer laboratory.

c. Flipped Classroom - e-learning predominates, students study at home through online courses, and attend school to work on individual projects. This model allows teachers to use study time not only for traditional lectures, but also for alternative work.

d. Individual Rotation - implies that the student has an individual schedule for studying the course.

2.Flex model - online learning is essential for students. Individual training, work in small groups prevails. Trainers provide trainee support as needed. Consultations can take place online or in person.

3. A La Carte model - allows students to take an online course that is enrolled in addition to other full-time courses. Provides the opportunity for simultaneous study in various institutions and a more in-depth study of the subject. 
4. Enriched Virtual - combines face-to-face and distance learning. Enriched Virtual programs started out as online schools and then developed blended programs to provide learners with a hands-on experience [9].

Each blended learning model is flexibly integrated into the educational process and makes it more effective. Key benefits of using blended learning models:

- maintaining the traditional teaching approach using modern digital technologies;

- $\quad$ students do not depend on the class schedule and can flexibly plan their studies in a convenient format;

- $\quad$ reduction of financial costs;

- $\quad$ interactive and personal interaction with the teacher and other students.

To introduce blended learning models into the educational process, it is necessary to make changes to the curriculum, develop methodological support, retrain and improve the qualifications of teachers, create infrastructure and equip high-tech classrooms.

The teacher's role in the blended learning process changes and instead of a translator of ready-made material, he turns into a consultant and mentor who helps the student to build an individual learning path. The effectiveness of pedagogical activity lies in the use of individual approaches, coordination of students' studies, communication with students on site and remotely, as well as monitoring and analyzing learning outcomes. Students, in turn, turn from passive consumers of the educational product into active participants in the educational process.

For example, blended learning models are being successfully implemented in the training of modern engineers. Part of the educational process takes place in classrooms where powerful equipment, software systems and innovative digital technologies are installed. Students have the opportunity to master the theoretical material through online courses, which were prepared by leading taught universities. Practical classes are held in scientific and educational centers with experienced specialists and scientists.

So in BMSTU prepare engineers using the "Russian method" of training engineering personnel, new educational methodologies, as well as new information technologies based on expert and intelligent systems $[10,11,12]$.

For the mathematical training of engineers at the university, a new technology was developed based on the use of an information and educational environment. The developed technology for training engineers automatically forms the educational process in accordance with the specified output competencies. These methods and technologies have a beneficial effect on the quality of training competitive engineering personnel and increasing the level of knowledge of students [13].

Thus, in a blended learning model, teachers can comfortably manage the educational process and integrate the latest digital technologies into it $[14,15]$.

Arizona State University and consulting company BCG have conducted research on how online and blended learning models affect the quality of education. They concluded that students who studied online and in person were less successful than those who studied in a mixed model [16].

In [7], the authors analyzed student performance in blended education versus traditional face-to-face programming in a programming course. As a result, they came to the conclusion that blended is more effective for both students and teachers.

The work [17] describes the benefits of blended learning and presents the results of research on how it is perceived by students and teachers. The authors used a 5-point Likert scale in their research and obtained the following results: $73.4 \%$ of the samples, that is, teachers, parents and students, are positive about the blended approach and 58.6\% believe that blended learning can improve the professional skills of teachers and students. The researchers concluded that the blended approach offers students time to process information 
at their own pace, which has a positive effect on their academic performance [18]. An automated testing system collects more data on how students perform their work. This data helps teachers to better analyze learning outcomes. Blended education enables educators to deliver unique content to learners using technology.

Although integrated blended learning programs provide the best results, educators use blended learning in individual courses, but not as a curriculum and thus do not exploit the main potential of blended learning effectiveness [4].

The European University Association conducted a study on the use of electronic technologies in teaching by European universities [19].

E-learning technologies are implemented by the majority of respondents (a total of 245 educational institutions were interviewed). However, universities use e-learning to varying degrees. Online courses and blended learning are the most popular directions for use in the educational process. More than half of universities use e-learning in all faculties, and 33\% in certain departments. This usually depends on the academic discipline. Blended learning programs are used by $55 \%$ of universities, online training programs - 39\%, online training organized in conjunction with other educational institutions - $40 \%$, but respondents said they plan to develop them.

The data obtained indicate a very modest level of implementation of e-learning in the educational process and its huge potential for further development.

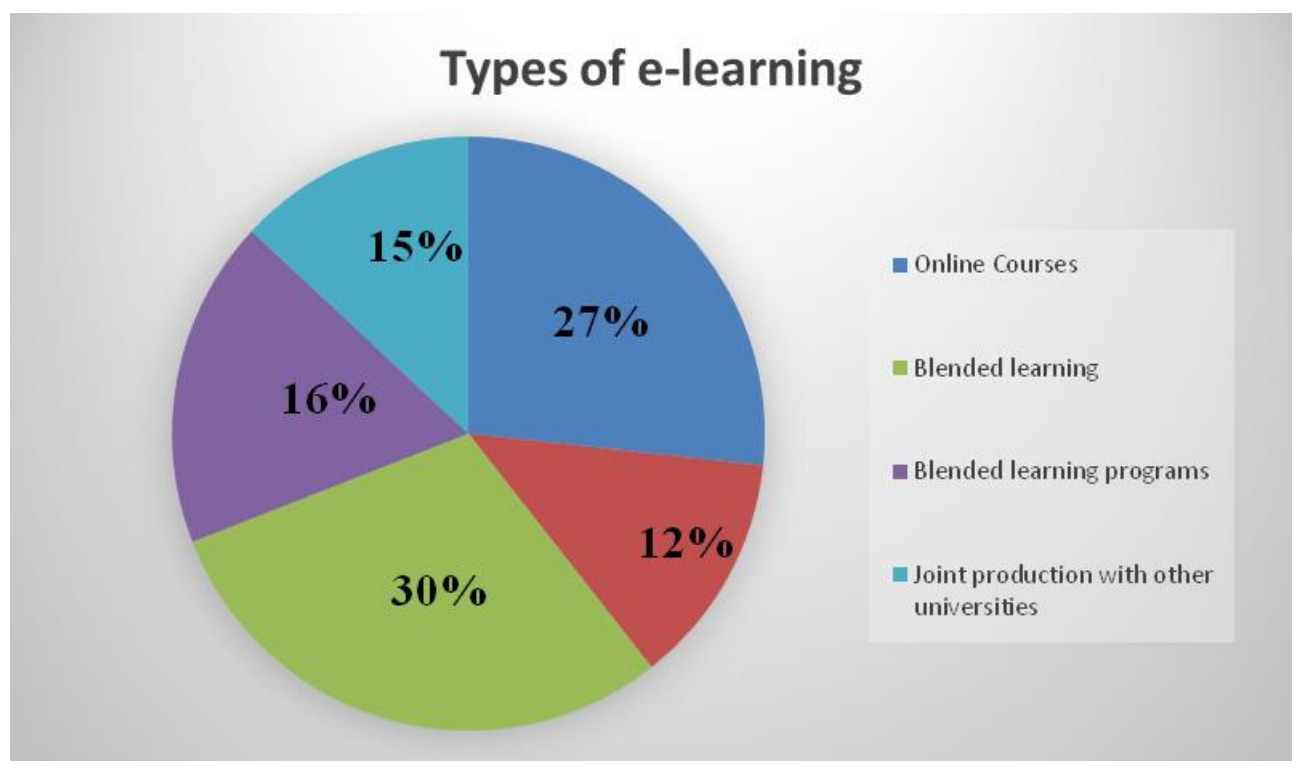

Fig. 1. Types of e-learning.

\section{Networking}

The rapid development of high technologies increases the competition between educational organizations and expands the international space. Modern, actively developing universities strive to strengthen their competitive positions in the international arena of the educational market. One means of achieving this goal is the development of strategic partnerships with other universities, in particular in the form of networking.

The network form of implementation of educational programs is the organization of training using the resources of several organizations carrying out educational activities, as 
well as, if necessary, using the resources of other organizations, including foreign ones [20].

This format of education is used to train highly qualified specialists, improve the quality of educational services, expand students' access to modern teaching aids and educational technologies, provide students with the opportunity to choose their own educational trajectory, in-depth study of courses and disciplines, develop unique competencies, and effectively use educational resources. increasing the competitiveness of graduates of an educational organization in the Russian and international markets.

Network contracts allow integrating education, science and production [21, 22,23]. The purpose of this integration is to pool human, material, technical and financial resources.

For mutually beneficial interaction between enterprises and educational institutions, it is important:

- form educational programs of universities with the involvement of enterprises;

- organize professional practice, internships and research work at enterprises, develop professional competencies of students;

- finance targeted training, provide grants and scholarships for students and teachers;

- create material and technical support.

The partnership of enterprises with educational organizations provides long-term staffing for the country's economy.

The development of networking and collaborative learning programs has become part of the internationalization of universities around the world [22].

There are many methods of implementing network interaction between organizations, we will consider the network form of blended learning [22,23].

The online form of blended learning involves the conclusion between the base organization and the organization - the partner of the agreement, which establishes the conditions for interaction and the procedure for the joint implementation of educational programs. Organizations carrying out educational activities, scientific organizations, medical organizations, cultural organizations, physical culture and sports and other organizations that have the resources necessary to carry out training, conduct educational and industrial practice and carry out other types of educational activities provided for by the relevant educational program. That is, the basic organization includes modules of educational programs of partner organizations in the educational program. On the basis of the concluded agreement, the base organization sends its students to master the chosen discipline to the partner organization, and then counts the learning outcomes and the corresponding labor intensity towards the development of its program. The online form of blended learning can be carried out in full-time form and using distance educational technologies and resources. Despite the fact that the number of face-to-face classes can be replaced by video lectures, web conferences, the teacher's workload is not reduced, but redistributed to other work.

Thus, the university can include an online course in its educational program by concluding a network agreement with the developer (partner organization) of the course or send its students to master the chosen discipline in person. Online courses are aggregated by modern educational platforms offering online courses in various disciplines. Thus, the host organization can use the resources of the partner organization in the form of open online courses hosted on the portal.

After completing the online course and successfully passing the test events, the student has the opportunity to receive a certificate and take this course at his university. 
To implement blended learning in a network form, it is necessary to make changes to the local acts of the university and to develop legal and regulatory frameworks governing the corresponding educational program and individual student curriculum.

Organizational support of network interaction:

- $\quad$ organizational and technical support;

- financial security;

- $\quad$ analysis of effectiveness and efficiency.

- The procedure, conditions and sources of funding for networking programs are determined by the agreement on the network form of blended learning. Funding can be provided by:

- own funds of the parent organization or partner organization;

- $\quad$ subsidy funds received by the parent organization;

- personal funds of students.

Benefits of network contracts in blended learning:

- $\quad$ equality of students around the world;

- accessibility of education;

- improving the quality of education;

- providing the student with a choice of their own educational trajectory;

- the possibility of forming unique competencies in demand in rapidly developing sectors of the economy;

- training of specialists at the junction of various areas of science and technology;

- the opportunity to exchange experience in personnel training and professional development of teachers;

- the possibility of using in educational activities the material and human resources of other educational organizations, including scientific, industrial, medical, etc .;

- implementation of the best domestic and foreign practices in the educational process;

- expanding students' access to modern educational technologies and teaching aids;

- $\quad$ synergistic effect;

- reducing the costs of an educational organization due to the effective use of educational resources;

- $\quad$ application of independent control of students' knowledge;

- freeing up part of the teachers' time for scientific work without increasing the number of staff.

As a rule, educational programs are interdisciplinary, based on the principles of integrating the content of education in various subject areas, profiles, areas of training at the intersection of branches of knowledge.

For the student, the importance of the agreement on the network form of implementing mixed educational programs is to expand access to modern educational technologies and teaching aids, to use the opportunity for in-depth study of courses, subjects, disciplines (modules), in cooperation with scientists from prestigious research centers.

This form of training allows the student to master the theoretical material through online learning, and to carry out the practical and research part in innovation centers with a team of professionals.

Despite the fact that online blended learning has significant advantages and effectiveness over traditional and online education, there are a number of reasons for its ineffective use: 
- lack of legal and regulatory frameworks governing the relevant educational program;

- limited funding for content development and infrastructure for the development of online blended learning;

- discrepancy and lagging of educational programs from modern educational opportunities;

- $\quad$ lack of teaching staff in the field of blended learning technologies;

- lack of technical and software equipment.

\section{Prospects for networked engineering education based on the Open BMSTU platform}

The training of modern engineers is inextricably linked with high technology and innovation. Technical universities, including BMSTU are in constant search of new development mechanisms and the creation of a promising management system.

In order to develop modern digital technologies in the educational activities of the BMSTU developed the information and educational platform Open BMSTU [24].

There are 2 main subsystems on Open BMSTU platform: the BMSTU-online platform contains electronic educational resources in the form of online courses in general technical disciplines, and Electronic Educational Resources (EER) storage system designed for distance learning. The BMSTU-online platform can be used as a tool for blended learning. Each course includes thematic video lectures and video seminars with 3D animation, tasks for independent work, test tasks and control testing with automated verification of results.

The main functionality of the platform:

- integration of digital educational resources of BMSTU;

- implementation of online education;

- implementation of blended digital education.

The technologies used in the training of engineers make it possible to form the process of teaching technical and mathematical courses, taking into account the specifics of a certain specialization [13].

The unique development of the university is the Digital Learning System Nomotex (DLS Nomotex). It is a multilevel hierarchical neural network model of mathematical knowledge with logical connections between individual elements of mathematical disciplines.

The Department "Computational Mathematics and Mathematical Physics" (FS-11) of BMSTU conducted a study on how DLS Nomotex affects student performance. For this study, 3 groups of first-year students from the faculties of "Power Engineering" and "Fundamental Sciences" were selected. Uncertified students were not taken into account, since in addition to poor academic performance, the reasons for expulsion may be different (health status, family circumstances, academic leave). In 2018, 56 students from three different groups took courses in linear algebra, calculus, integrals and differential equations in a traditional form of study. In 2019, the next stream of first-year students, consisting of 63 students, studied these disciplines using blended learning and the application of the DLS Nomotex mathematical knowledge base. All courses that included blended learning showed a significant increase in the number of excellent marks and a decrease in the number of satisfactory marks, according to the test sheets. The teachers noted that the number of retakes has decreased. Figures 2-4 show graphs comparing the final performance (including retakes) of traditional and blended learning using DLS Nomotex. 


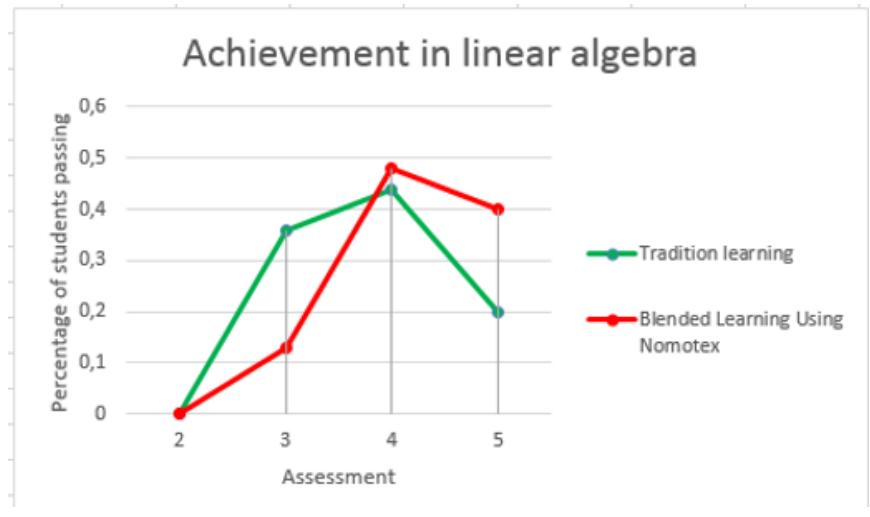

Fig. 2. Achievement in linear algebra.

\section{Achievement in Integrals and Differential Equations}

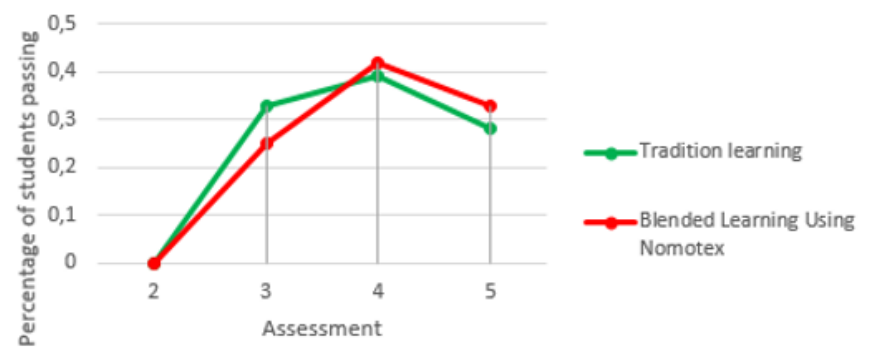

Fig. 3. Achievement in integrals and differential equations.

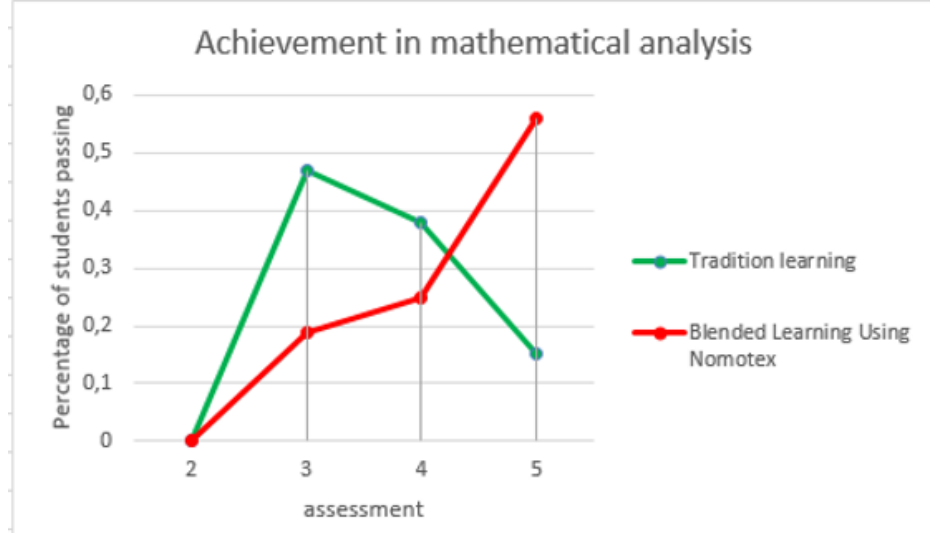

Fig. 4. Achievement in mathematical analysis.

The increase in academic performance is due to the fact that students have unlimited access to educational materials. They study each topic at their own pace, and when questions arise, they turn to the teacher for help.

Interactive engineering examples of the application of mathematical knowledge increase motivation and interest in learning, students understand where and how the acquired knowledge can be used. The structure of DLS Nomotex is built in such a way that the student can use it as an encyclopedia. Review past material and explore new topics. 
The ability to take control and independent work with automatic verification eliminates the subjectivity of teachers, and also helps to track in which issues the student has problems.

Thus, the use of interactive and electronic courses in the educational process has a positive effect on student performance.

The progressive directions of development of technical universities are joint educational programs and new forms of cooperation, for example, network engineering education. Networking allows universities to increase their educational, personnel, software and methodological, material and technical and information potential through the use of electronic educational resources of other organizations.

In fig. 5 shows a diagram of the network interaction of technical universities on the example of BMSTU. It consists in the integration of the developer of the information and educational environment and many technical universities - partners, which, on the basis of an agreement, include in their curricula electronic educational resources of BMSTU. That is, technical universities use the functionality of the Open BMSTU platform to replace part of their courses with blended learning.

On the Open BMSTU platform, an individual educational program is formed for students in a specific field of engineering training, and appropriate disciplines and courses are selected. Training can take place both in classroom form using interactive panels, and through online courses. Blended learning allows students to master the material more deeply and work out certain topics in a quality manner. Lectures and seminars use modern computer technology to help students visualize mathematical concepts. Classes are interesting and productive.

After successfully mastering the material and passing the control measures, the student has the opportunity to receive a certificate and take the chosen discipline at his university.

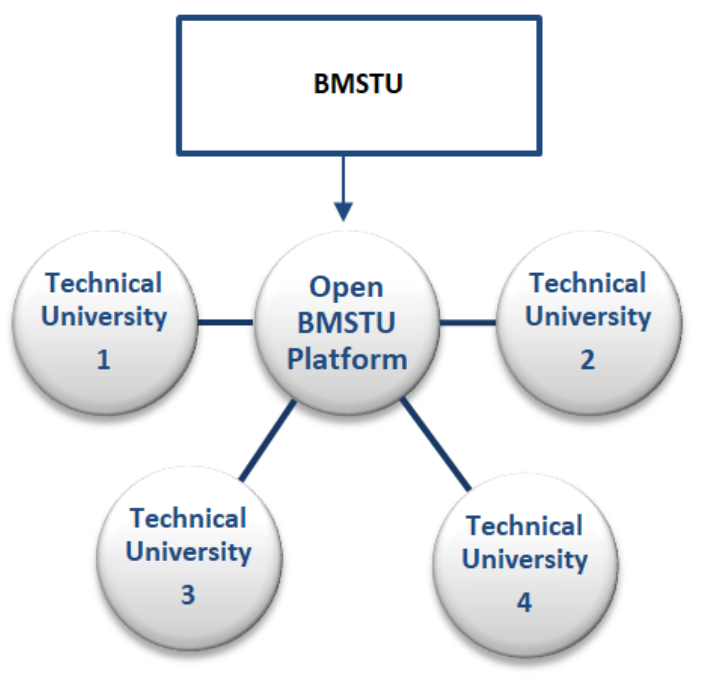

Fig. 5. Scheme of network interaction based on the Open BMSTU platform.

This integration of universities ensures the sustainable development of engineering education in Russia. A unique educational environment is being created in which students can fully reveal their potential and gain knowledge and experience at the country's leading universities. 


\section{Conclusion}

Higher education has successfully applied the concept of blended learning, which combines e-learning and classroom learning. These blended education programs are as effective as, and often superior to, face-to-face programs.

To introduce blended learning into the educational process and create strategic partnerships, expand the exchange of knowledge and practices, pool resources among educational organizations, network interaction is used. Networked blended learning expands the scope of traditional education and allows students to reach their full potential. Improving the quality of personnel training is carried out through the rational use of the available material, technical, educational, methodological, informational and human resources of educational organizations.

To create unique engineering training competencies, technical universities are applying networked engineering education. At the BMSTU developed a new technology for training engineers based on the use of information and educational environment. This environment provides technical universities with access to electronic educational resources of BMSTU. Such cooperation has a beneficial effect on the quality of training competitive engineering personnel and increasing the level of knowledge of students.

Cooperation and partnership with other educational institutions increase the prestige and competitiveness of the university in the international educational arena, attracts students from all over the world, allows you to use progressive teaching methods, generate additional income and save budget.

For the successful implementation of network interaction, it is necessary to create common educational programs, motivate students and teachers, create a regulatory framework, attract funding for the creation of interuniversity research centers and model new management processes in an educational organization.

\section{References}

1. V. Arkorful \& N. Abaidoo, The role of e-learning, advantages and disadvantages of its adoption in higher education, International Journal of Instructional Technology and Distance Learning, 12(1), pp. 29-42 (2015)

2. J. Peraza, R. Estrada-Lizárraga, A. Zaldívar-Colado, R. Mendoza-Zatarain, M. Olivarría \& J. Cobián, IMPORTANCE OF IMPLEMENTING OPTIMAL LEARNING MANAGEMENT SYSTEMS FOR E LEARNING IN HIGHER EDUCATION, In ICERI2012 Proceedings, pp. 530-535, IATED (2012)

3. T. Yigit, A. Koyun, A.S. Yuksel \& I.A. Cankaya, Evaluation of blended learning approach in computer engineering education, Procedia-Social and Behavioral Sciences, 141, pp. 807-812 (2014)

4. D. Steffens \& M. Reiss, Performance of blended learning in university teaching: determinants and challenges, eleed, 6(1) (2010)

5. H.H. Yang \& J. MacLeod, Blended Learning in Teacher Education, In Oxford Research Encyclopedia of Education (2019)

6. V. Spiliotopoulos, Towards a technology-enhanced university education, In Blended learning across disciplines: Models for implementation, pp. 1-16, IGI Global (2011)

7. T. Yigit, A. Koyun, A.S. Yuksel \& I.A. Cankaya, Evaluation of blended learning approach in computer engineering education, Procedia-Social and Behavioral Sciences, 141, pp. 807-812 (2014) 
8. L. Bielawski \& D.S. Metcalf, Blended elearning: Integrating knowledge, performance, support, and online learning, Human Resource Development (2003)

9. M.B. Horn \& H. Staker, Blended: Using disruptive innovation to improve schools, John Wiley \& Sons (2014)

10. A.A. Aleksandrov, K.A. Neusipin, A.V. Proletarsky \& K. Fang, Innovation development trends of modern management systems of educational organizations, Proceeding of 2012 International Conference on Information Management, Innovation Management and Industrial Engineering, ICIII 2012, 3, pp. 187-189 (2012)

11. E.V. Smirnova, A.A. Dobrjkov, A.P. Karpenko \& V.V. Syuzev, Mentally structured educational technology and engineers preparation quality management, Communications in Computer and Information Science, 754, pp. 119-132 (2017)

12. O. Scherbakova, O. Otrokova \& V. Burenina, Russian Method of Training Engineering Personnel: Historical Experience and Modernity, In 4th International Conference on Contemporary Education, Social Sciences and Humanities (ICCESSH 2019), Atlantis Press (2019)

13. Y.I. Dimitrienko \& E.A. Gubareva, Neural network model of mathematical knowledge and development of information and educational environment for mathematical training of engineers, Journal of Physics: Conference Series, Vol. 1141012010 (2018)

14. J.H. Kim, D.M. Baylen, A. Leh \& L. Lin, Blended learning in teacher education: Uncovering its transformative potential for teacher preparation programs, In Handbook of Research on Enhancing Teacher Education with Advanced Instructional Technologies, pp. 166-185, IGI Global (2015)

15. S. Pal, T.Q. Cuong \& R.S.S. Nehru (Eds.), Digital Education Pedagogy: Principles and Paradigms, CRC Press (2020)

16. Allison Bailey, Nithya Vaduganathan, Tyce Henry, Renee Laverdiere, Lou Pugliese Making digital learning work [Electronic resource].

URL: https://edplus.asu.edu/sites/default/files/BCG-Making-Digital-Learning-WorkApr-2018\%20.pdf (accessed: 10/11/2019)

17. C. Arundhathi Bai, Y. Chakradhara Singh, A Study on Outcomes of Blended Learning, IUT Journal of Advance Research and Development Volume-4, No. 2 October 2018 March 2019, pp. 48-55(2019)

18. B.R. Stockwell, M.S. Stockwell, M. Cennamo \& E. Jiang, Blended learning improves science education, Cell, 162(5), pp. 933-936 (2015)

19. [Electronic resource]. URL: https://eua.eu/downloads/publications/elearning\%20in\%20european\%20higher\%20education\%20institutions $\% 20$ results $\% 20 \mathrm{of}$ $\% 20$ a\%20mapping\%20survey.pdf (accessed: 10/02/2020)

20. B. Tolysbayev, T. Uteubayev \& G. Amirova, Network Interaction of Science, Education and Production, In MATEC Web of Conferences, Vol. 297, p. 08003, EDP Sciences (2019)

21. L. Luchikhina, Characteristics of the Networking Interaction among the Universities of Germany,In "Humanities and Social Sciences: Novations, Problems, Prospects"(HSSNPP 2019), Atlantis Press, (2019)

22. G.A. Krasnova \& V.A. Teslenko, Analysis Of Main Models Of Educational Institutions Network Interaction, University Management: Practice and Analysis (2017)

23. T.J. van Weert \& D. Wood, Network-blended education of tomorrow, In Education and the Knowledge Society, pp. 257-263, Springer, Boston, MA (2005)

24. [Electronic resource]. URL: https://open.bmstu.ru/ (accessed: 12/02/2020) 